\title{
El potencial empresarial en los universitarios de Sevilla desde una perspectiva de género
}

\author{
María José RODRÍGUEZ GUTIÉRREZ*
}

\section{RESUMEN}

La participación de la mujeres en la actividad empresarial en Andalucía, aun cuando se ha incrementado de forma progresiva en los últimos años, es todavía escasa. A partir de diversos trabajos sobre la actividad empresarial en Andalucía, se deduce que la débil tasa de emergencia empresarial de la región, considerada una de las razones que explican su atraso económico en comparación con otras regiones españolas y europeas, se podría incrementar estimulando la aparición de mujeres empresarias de calidad, capaces de impulsar a través del tejido empresarial el desarrollo económico de esta región. Desde tal perspectiva, en el presente trabajo se pretende profundizar en el conocimiento del potencial empresarial femenino en la provincia de Sevilla, dado que resultaría de gran utilidad comprender cuales son los principales obstáculos que impiden a las potenciales empresarias de Sevilla emprender una actividad empresarial, y cuales las motivaciones que les inducen a dedicarse a este tipo de ocupación. De esta manera, las instituciones públicas y sociales podrán adaptar mejor sus programas políticos y económicos dirigidos a reforzar el tejido empresarial y fomentar la creación de empresas gestionadas por empresarias eficientes, innovadoras y dinámicas.

\section{ABSTRACT}

The participation of women in entrepreneurship activities in Andalusia, despite has been progressively growing in the recent years, is still limited, being deduced based on several studies about it, that the weak rate of entrepreneurship emergence,

\footnotetext{
* Profesora del Departamento de Economía Aplicada I. Universidad de Sevilla.
} 
considered as one of the reasons that explain its economical backwardness regarding other Spanish and Europeans areas, could be increased by stimulation of entrepreneur women of high quality, who are able to impulse the economical development of Andalusia through the entrepreneurship network. From this perspective, this work intends to study in depth the knowledge about the women entrepreneurship capacity in Sevilla, due it would be highly useful to understand what are the main obstacles that avoid potential female entrepreneurs in Sevilla to launch a entrepreneurship activity and what are the motivations that push them to choose this way. Therefore, public and social institutions will be able to better adapt their political and economical programs in order to strength the entrepreneurship network and impulse the creation of business managed by efficient, innovator and dynamic female entrepreneurs.

\section{EL POTENCIAL EMPRESARIAL FEMENINO Y LOS PROCESOS DE DESARROLLO ECONÓMICO EN ANDALUCÍA}

Desde hace ya algunos años se puede observar una creciente preocupación por avanzar en el conocimiento de la función empresarial y del papel que juega el empresario en los procesos de desarrollo económico. Esta inquietud se ha intensificado a raíz del nacimiento en la década de los ochenta de los nuevos modelos de desarrollo endógeno, en los que se resalta la influencia de los recursos económicos, institucionales, humanos y culturales de un territorio en su potencial de desarrollo. Desde este punto de vista, cobra especial importancia el dinamismo de las empresas locales, especialmente las pequeñas y medianas empresas, la capacidad empresarial del territorio, y las decisiones de inversión y comportamientos creativos e innovadores de empresarios emprendedores y con capacidad de iniciativa. No obstante, para que una región se desarrolle económicamente, no sólo resulta necesario la existencia de unos empresarios de calidad que sostengan un tejido empresarial competitivo con capacidad de generar empleo, sino que también se requiere el surgimiento de una fuerza emprendedora local, para lo cual es necesario la existencia de potenciales empresarios, individuos con una actitud favorable hacia el desempeño de las funciones empresariales. En este sentido se pronuncia Shapero al señalar en su conocida obra Self-renewing economies, que el desarrollo económico de una sociedad no depende del volumen existente de empresarios en un momento determinado, sino de su nivel de potencial empresarial o potencial para aumentar la actividad empresarial. 
Por otro lado, en diferentes foros internacionales se ha señalado que tanto en las regiones desarrolladas como en las subdesarrolladas se está utilizando de forma insuficiente el potencial empresarial femenino, la capacidad de las mujeres para impulsar a través de su actividad empresarial el desarrollo económico. De hecho, en todas las provincias de la región andaluza la participación de la mujeres en la actividad empresarial es bastante inferior a la participación masculina, deduciéndose a partir de diversos trabajos sobre la actividad empresarial en Andalucía que la débil tasa de emergencia empresarial de la región, considerada una de las razones que explican su atraso económico en comparación con otras regiones españolas y europeas, se podría incrementar estimulando la aparición de mujeres empresarias de calidad, capaces de impulsar a través del tejido empresarial el desarrollo económico de esta región. En efecto, según los datos de la EPA, el volumen de personas ocupadas en Andalucía como empresarios, con o sin asalariados, ascendía en el año 2000 a aproximadamente 370,3 miles de personas, lo que supone alrededor del $17 \%$ de la población ocupada de la región, porcentaje que a nivel nacional supera el $17,6 \%$ del total de población ocupada. Esta pequeña diferencia se debe fundamentalmente a la menor participación de las mujeres en la actividad empresarial, pues mientras que en Andalucía el porcentaje de mujeres ocupadas en actividades empresariales respecto al total de población empresarial es del $23,8 \%$, la proporción a nivel nacional se eleva hasta el $26,95 \%$.

Desde tal perspectiva, parece interesante profundizar en el conocimiento del potencial empresarial femenino en Andalucía, y dado que la mayor parte de los investigadores de la teoría del empresario coinciden en afirmar que el potencial empresarial de una sociedad no está determinado de antemano, sino que es posible influir en los individuos que conforman una sociedad orientándolos en mayor o menor medida hacia la actividad empresarial, resultaría de gran utilidad comprender cuáles son los principales obstáculos que, según las potenciales empresarias de la región, les impiden emprender una actividad empresarial y cuáles las motivaciones que les inducen a dedicarse a este tipo de ocupación. De esta manera, las instituciones públicas y sociales de la región podrán adaptar mejor sus programas políticos y económicos dirigidos a reforzar el tejido empresarial y fomentar la creación de empresas gestionadas por empresarias eficientes, innovadoras y dinámicas.

Con este objetivo, en el presente trabajo se pretende analizar algunos elementos determinantes del potencial empresarial en la provincia de Sevilla desde 
una perspectiva de género. Para ello, se propone en primer lugar un marco teórico en el que se trata de exponer un concepto claro y operativo del potencial empresarial que permita aproximarse al conocimiento de los factores que inciden sobre los potenciales empresarios, así como los mecanismos a través de los cuales se manifiestan estas influencias. A continuación, se plantean, sobre la base de una amplia revisión de los diferentes estudios teóricos y empíricos realizados en torno a las características y comportamientos diferenciales de las mujeres empresarias, algunas hipótesis acerca del potencial empresarial femenino. En tercer lugar, desde un punto de vista empírico, y con base en el anterior marco teórico, se intentará descubrir cuáles son las motivaciones que impulsan a los potenciales empresario/as de la provincia de Sevilla a iniciar una actividad y cuáles las diferencias existentes entre ambos sexos en cuanto a la forma de percibir los obstáculos y oportunidades existentes en el entorno para emprender una actividad empresarial, lo que ayudará a comprender por qué es tan reducida la participación de las mujeres de la provincia en una actividad económica directamente relacionada con su desarrollo. En este sentido, dado que diferentes investigaciones acerca del empresario han relacionado la emergencia empresarial con el nivel de formación del individuo, el análisis se realizará sobre una muestra de estudiantes de la Universidad de Sevilla que están realizando estudios directamente relacionados con la actividad empresarial. Los resultados obtenidos de este análisis permitirán conocer algunas de las diferencias existentes entre los potenciales empresarios universitarios de Sevilla según su sexo que puede resultar de alguna utilidad para determinar qué políticas económicas son más adecuadas para la promoción de la emergencia empresarial de mujeres en esta provincia.

\section{DETERMINANTES DEL CONCEPTO DE POTENCIAL EMPRESARIAL}

Las primeras investigaciones cualitativas en torno a la actividad empresarial se centraron en el análisis de los factores que impulsan la aparición de nuevos empresarios o emergencia empresarial, la cual constituye uno de los dos componentes del espíritu empresarial de una sociedad. La emergencia empresarial surge del desempeño de la función promotora de empresa, que corresponde, según señala el profesor Guzmán Cuevas al describir las funciones del empresario en la economía (Guzmán, 1995), a los empresarios potenciales, aquellos individuos que van a crear, iniciar o emprender una nueva empresa. Para este autor, el potencial empresarial de un individuo va a estar constituido por dos componentes: su "orientación hacia el trabajo por 
cuenta propia", que constituye una condición necesaria pero no suficiente, ya que no solo el empresario trabaja por cuenta propia, (también lo hacen otros trabajadores autónomos), y su "propensión hacia el empresariado".

La orientación hacia el trabajo por cuenta propia indica la preferencia del individuos por el desempeño de un trabajo por cuenta propia frente a la opción de trabajar por cuenta ajena. Esta preferencia puede ser una manifestación de una característica personal del individuo que, según diversas investigaciones, está presente en gran medida en los empresarios: el deseo y necesidad de independencia, la cual conduce a los potenciales empresarios a preferir trabajar por cuenta propia para poner en práctica sus propias ideas, evitando someterse a la autoridad derivada de la estructura jerárquica propia de los trabajos por cuenta ajena (Collins y Moore,1964). No obstante, para que una persona muestre un cierto potencial empresarial es necesario que además presente una propensión o predisposición hacia la actividad empresarial, la cual viene dada por una serie de elementos que determinan la probabilidad que el individuo cree que tiene para llegar a convertirse en empresario, probabilidad que este estimará más alta cuanto más positiva sea su percepción acerca de la viabilidad de iniciar una actividad empresarial con éxito.

En función de estos dos elementos, el nivel de potencial empresarial de una sociedad dependerá del porcentaje de personas con orientación hacia el trabajo por cuenta propia que estimen probable o muy probable la posibilidad de que algún día se conviertan en empresarios, definición de la cual se puede deducir que el potencial empresarial dependerá de las "preferencias" de los individuos relacionadas con sus opciones laborales y de sus "percepciones" acerca de la viabilidad de hacer realidad esas preferencias mediante el desempeño de una actividad laboral.

Por otro lado, las preferencias de los potenciales empresarios respecto a la actividad empresarial frente a otras actividades laborales alternativas dependerán de cuáles sean sus percepciones acerca de la conveniencia de desarrollar tal actividad (Krueger, Reilly y Carsrud, 2000). El potencial empresario es un individuo que actúa racionalmente, procesando toda la información disponible y decidiéndose a aprovechar o no una oportunidad disponible comparando los resultados subjetivos de iniciarse en la actividad empresarial con los rendimientos subjetivos de una actividad alternativa. Cuanto mayores sean los rendimientos intrínsecos (vinculados a la satisfacción obtenida a partir de los resultados directos de la acción en el propio 
sujeto que la realiza, no como respuesta del entorno: satisfacción, realización, independencia...), extrínsecos (relacionados con las recompensas y castigos con que el entorno responde a la acción del individuo, como, por ejemplo, poder, dinero, reconocimiento, empleo...), o transcendentales (referidos a las consecuencias que la acción realizada puede tener para otras personas, con independencia del resultado inmediato para quien la realiza, como son la ayuda a los demás, el cuidado de los hijos, etc.) que el potencial empresario percibe que podrá obtener si se decide a iniciar una actividad empresarial en comparación con otras, mayor será su preferencia por esta actividad y más positiva su actitud hacia la misma.

A su vez, estos rendimientos, que pueden ser tanto positivos (incentivos) como negativos (desincentivos), serán valorados por el potencial empresario de forma diferente dependiendo de cuáles sean los "motivos" que le inducen a decantarse por esta actividad, por lo que se puede admitir que los motivos del potencial empresario van a afectar a sus intenciones de iniciar una actividad empresarial. De hecho, son varios los autores que consideran que las motivaciones influyen en los comportamientos empresariales, estableciéndose que los motivos pueden llegar a ser un indicador del esfuerzo que el individuo planea realizar para llevar a cabo un comportamiento (Ajzen, 1991). Al mismo tiempo, los motivos del potencial empresario se van a ver condicionados por sus "características personales", y desde un punto de vista sociocognitivo, por los factores de su "entorno personal y global" (Velaz, 1996).

En definitiva, el potencial empresarial de un individuo depende de sus preferencias 0 actitud respecto a esta actividad, así como de su propensión hacia la misma. Ambos conceptos van a estar condicionados por las propias percepciones de los potenciales empresarios (respecto a la viabilidad de emerger como empresario y respecto a los rendimientos o resultados de todo tipo que puede alcanzar si se decide a desarrollar dicha actividad), por lo que, asumiendo que la percepción subjetiva de un hecho objetivo es el resultado de un proceso cognitivo, el potencial empresarial de un individuo, y por agregación, de una sociedad, variará en función de sus características personales, de sus motivos y de las circunstancias de su entorno (Figura 1). 
Figura 1. Determinantes del Potencial Empresarial.

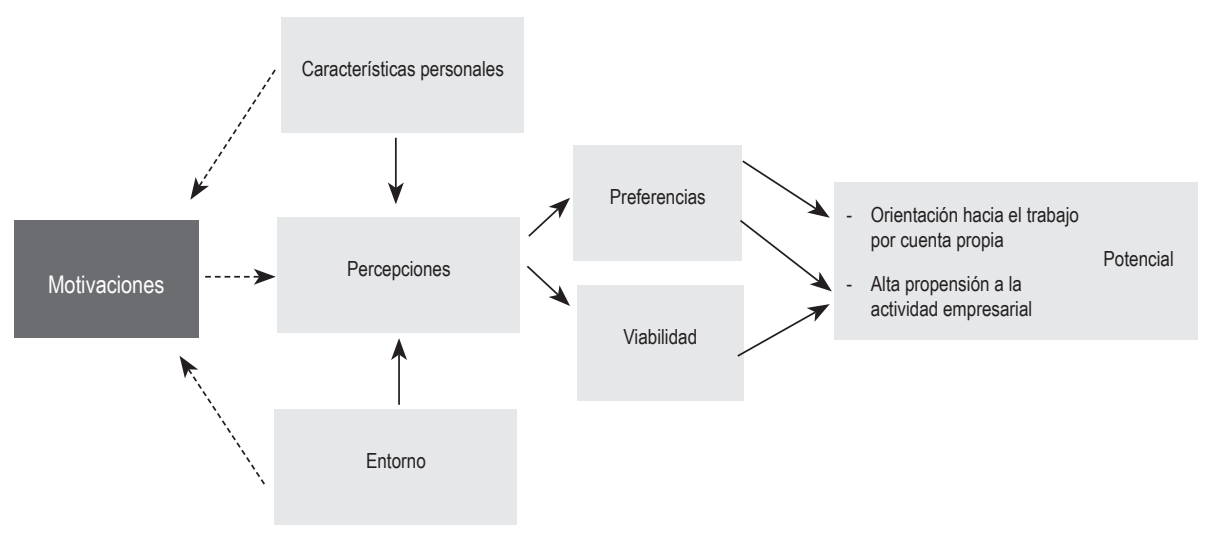

Fuente: Elaboración propia.

\section{EL POTENCIAL EMPRESARIAL FEMENINO}

Como viene siendo común en la evolución de todas las líneas de investigación de la teoría del empresario, son muy escasos los estudios llevados a cabo en torno al potencial empresarial femenino. En este sentido, se ha señalado que se conoce poco acerca de los factores que afectan al desequilibrio en la emergencia y potencial empresarial entre géneros porque la mayoría de los estudios sobre los aspectos femeninos de la relación empresarial se han realizado sobre muestras de empresario/ as que han desempeñado la función promotora de empresa con éxito, cuando los desequilibrios de género ya están materializados (Alsos y Ljunngren, 1998).

Solamente uno pocos autores (Scherer, Broszinski y Wiebe, 1990; Guzmán, 1995; Matthews y Moser, 1996; Cáceres, Guzmán y Rodríguez, 1996; Carter y Kolvereid, 1997; Alsos y Ljunggren, 1998; Mazarol; Volery, Doss y Thein, 1999) se han preocupado por investigar las diferencias de género en el proceso de emergencia empresarial a partir de muestras de potenciales empresarios. En algunos de estos estudios se ha llegado a la conclusión de que no hay diferencias en el potencial empresarial de ambos sexos, sino que las mujeres tienen que enfrentar mayores trabas y obstáculos para emprender una actividad empresarial que los varones (Alsos y Ljunnggren, 1998). Estos obstáculos serían de muy diversos tipos, pero en general tienen un origen sociocultural y se relacionan con la actitud de la sociedad en general respecto al rol desempeñado por la mujer, y los prejuicios acerca de su capacidad 
y habilidad para desempeñar determinadas actividades profesionales (Ferguson y Durup, 1997). En este caso, ambos sexos tendrían el mismo potencial empresarial, pero muchas mujeres no llegarían emerger como empresarias al no superar las mayores dificultades con las que se encuentran para emprender un negocio.

No obstante, en otros trabajos se afirma que el potencial empresarial femenino, o predisposición de las mujeres hacia la actividad empresarial, es más reducido que el masculino (Mazarol, Volery, Doss y Thein 1999), señalando esta razón como la causa de la baja participación de las mujeres en la actividad empresarial. En este sentido, es posible que la orientación y propensión hacia la actividad empresarial de las mujeres, y por tanto su potencial empresarial, se vea negativamente afectado por la desventajosa percepción que las mismas tienen de los diferentes obstáculos y oportunidades existentes para ambos sexos al inicio de la actividad empresarial. Sin embargo, diversos estudios sugieren que, en realidad lo que ocurre es que ambos sexos evalúan su entorno de una forma distinta y se forman impresiones dispares acerca de las dificultades existentes con relación a la emergencia empresarial (Kolvereid, Shane y Westhead, 1993). Para estos autores, las discordancias en la percepción del entorno entre ambos sexos se deben a las diferencias existentes en cuanto a los motivos que les impulsan a iniciar una actividad empresarial y a la desigual forma en que las características personales y elementos del entorno les afectan.

Desde este punto de vista, en la literatura que analiza los motivos y motivaciones que inducen a los individuos a crear o iniciar una actividad empresarial se ha observado, que, en general, existe una pluralidad de motivos diferentes por los que los potenciales empresarios se deciden a desarrollar una actividad empresarial. No obstante, parece que entre las mujeres predominan más los motivos de carácter intrínsecos (relacionados con aquellos elementos que atraen a los individuos hacia la actividad empresarial por circunstancias positivas, vinculadas a la satisfacción que la persona obtiene por el propio interés y placer derivado de la adopción de un comportamiento empresarial) y trascendentales (asociados con las consecuencias que la acción realizada puede tener para otras personas) que en los varones (Gatewood, Gartner y Shaver, 1995). De estos resultados, cabe esperar que las potenciales mujeres empresarias sean menos sensibles a aquellos elementos del su entorno vinculados a los motivos extrínsecos (relacionados con los elementos que empujan a los potenciales empresarios a iniciar una actividad empresarial buscando 
obtener una recompensa del entorno: rentabilidad, poder, reconocimiento, empleo...), como son el entorno socioeconómico y el político-institucional. Por el contrario, serán más sensibles a los elementos del entorno familiar y personal de los que dependen los motivos intrínsecos (autorrealización, deseo de logro, oportunidad de aplicar habilidades....) y trascendentales (cuidado de la familia, satisfacer necesidades de la sociedad....), como son la formación, experiencia laboral e influencia familiar.

\section{EL POTENCIAL EMPRESARIAL EN LOS UNIVERSITARIOS DE SEVILLA DESDE UNA PERSPECTIVA DE GÉNERO}

Una vez realizada una aproximación al concepto de potencial empresarial y establecidos sus determinantes, así como enunciadas algunas hipótesis sobre el potencial empresarial femenino, se va a proceder a analizar desde una perspectiva de género el potencial empresarial de la provincia de Sevilla a partir de la información extraída de una muestra de potenciales empresarios.

\subsection{Metodología en la obtención y tratamiento de la información}

Ante la inexistencia de una fuente de datos sobre los potenciales empresarios y los rasgos que les caracterizan, se procedió a realizar un estudio de campo del que se ha obtenido una amplia información sobre diversas cuestiones relacionadas con el potencial empresarial a través de las encuestas realizadas a una muestra de potenciales empresarios sevillanos. Esta muestra está constituida por estudiantes matriculados en varios cursos de las Licenciaturas de Económicas y de Administración y Dirección de Empresas, y de la Diplomatura de Ciencias Empresariales pertenecientes a la Facultad de Ciencias Económicas y Empresariales y a la Escuela de Empresariales de la Universidad de Sevilla durante el curso académico 2000/2001.

Se eligió esta muestra como representación de los potenciales empresarios sevillanos por varios motivos. En primer lugar, tal como ha quedado reflejado

anteriormente, diferentes investigaciones acerca del empresario han relacionado la emergencia empresarial con el nivel de formación del individuo, suponiendo que su potencial empresarial aumenta en la medida en que lo hace su formación. Por esta razón en diferentes estudios empíricos se ha considerado a los estudiantes universitarios como representantes de los potenciales emprendedores, especialmente 
a aquéllos que están realizando estudios directamente relacionados con la actividad empresarial (González y Guillén, 1996). En segundo lugar, no hay que olvidar que uno de los factores que más han contribuido a la transformación de los valores culturales de la sociedad con relación a los roles de género, favoreciendo de esta manera la presencia de mujeres en los diferentes sectores del ámbito laboral y empresarial, ha sido la afluencia masiva de las mismas a los niveles medio y superior de formación. Por esta razón, dado el objeto de la investigación, análisis del potencial empresarial femenino en la provincia de Sevilla, parece adecuado analizar ese potencial tomando como referencia aquella población femenina que en mayor medida ha contribuido a la transformación de los roles de género en materia empresarial.

A partir de un universo poblacional de 9.300 potenciales empresarios, se ha aplicado la formulación del muestreo aleatorio simple sin reposición para determinar el tamaño de la muestra. Para ello se ha considerado que la variable a estudiar de la muestra tiene carácter dicotómico y que el tamaño de la población es lo suficientemente grande como para considerarlo infinito. Finalmente se obtuvo una muestra de 278 alumnos a los que se les pasó un cuestionario de respuestas cerradas, lo que permitía agilizar su realización, evitaba las divagaciones y ayudaba a precisar y definir mejor las respuestas. En la figura siguiente aparece la distribución de dicha muestra según su sexo.

Gráfico 10. Distribución de los potenciales empresarios de la muestra según su sexo.

$(\%$ sobre $n=278)$.

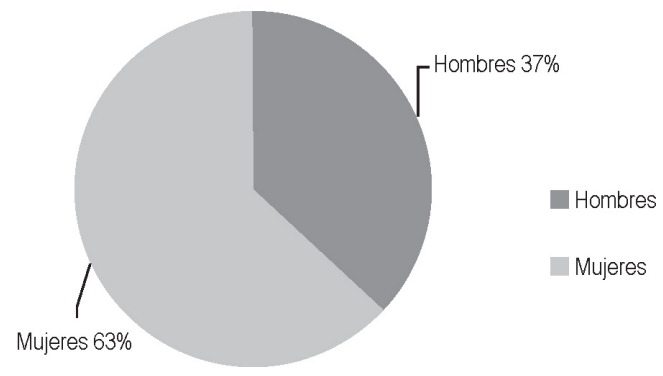

Fuente: Elaboración propia.

\subsection{Análisis del potencial empresarial}

A continuación se va a realizar un análisis del potencial empresarial en Sevilla, para lo cual se examinarán los elementos que configuran ese potencial empresarial: la orientación hacia el trabajo por cuenta propia y la propensión hacia la actividad 
empresarial. Esto permitirá conocer cuál es el nivel de potencial empresarial en la provincia de Sevilla.

Para medir la orientación hacia el trabajo por cuenta propia, se preguntó a todos los individuos de la muestra cuáles eran sus preferencias laborales suponiendo que todas las opciones les reportaran el mismo nivel de ingresos, encontrándose una significativa orientación hacia el trabajo por cuenta propia, ya que más del $65 \%$ de los individuos encuestados manifestaban preferir esta opción frente a otras posibles alternativas (Gráfico 11). Esto supone que aproximadamente dos de cada 3 estudiantes de la muestra prefieren trabajar por cuenta propia por lo que se puede deducir que la población de esta provincia se caracteriza por un fuerte deseo y necesidad de independencia, rasgo de personalidad que, como anteriormente se ha mencionado, se relaciona estrechamente con la orientación de los individuos hacia un trabajo por cuenta propia.

Gráfico 11. Preferencia de los potenciales sevillanos por el trabajo por cta. propia o ajena (\% sobre $n=278)$.

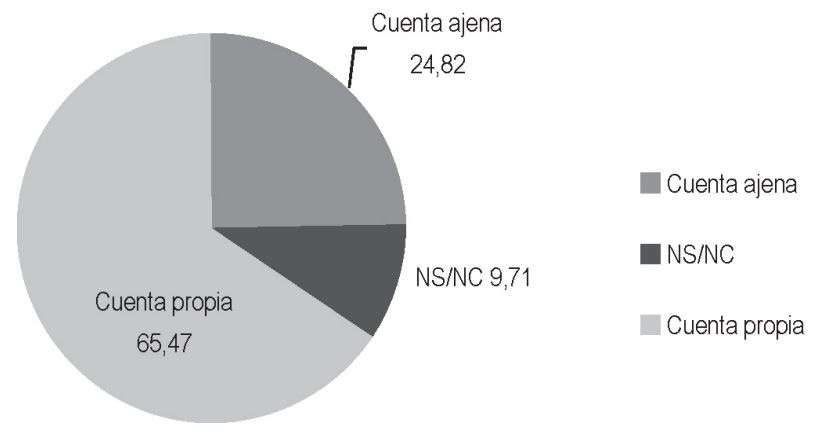

Fuente: Elaboración propia.

Estos resultados concuerdan con los obtenidos en otras investigaciones acerca del potencial empresarial de Sevilla. Así, en un estudio empírico realizado en la provincia de Sevilla en 1991 sobre una base de datos de 1.238 entrevistas personales referidas a residentes no empresarios de dicha provincia con edades comprendidas entre los 15 y 45 años, el profesor Guzmán Cuevas comprobó que aproximadamente el $69 \%$ de los individuos encuestados preferían trabajar por cuenta propia, porcentaje que aumentaba ligeramente si sólo se consideraban los individuos de edades comprendidas entre 15 y 25 años (Guzmán, 1995). 
Pero, como anteriormente se ha explicado, el deseo de trabajar por cuenta propia constituye una condición necesaria aunque no suficiente para determinar cuál es el potencial empresarial de un individuo. Además, es necesario que éste presente una cierta propensión hacia la actividad empresarial, variable que constituye el segundo elemento definitorio del potencial empresarial, y que nos indica cuál es la probabilidad que el individuo cree que tiene de llegar a emerger como empresario. Cuanto mayor sea esta probabilidad, más elevada es la propensión hacia la actividad empresarial de los individuos, de forma que se considera que una persona tiene un positivo nivel de potencial empresarial si muestra una orientación hacia el trabajo por cuenta propia y considera probable o muy probable llegar a desempeñar una actividad empresarial.

Para medir la propensión a la actividad empresarial se preguntó a los estudiantes que conforman la muestra y que habían respondido anteriormente preferir un trabajo por cuenta propia cuál creían que era la probabilidad de convertirse en un futuro en titular de una empresa. El 53,3\% respondió muy probable o probable, lo que supone, desde una perspectiva global, que el deseo o necesidad de trabajar por cuenta propia se reduce a algo más de la mitad cuando el potencial empresario evalúa realmente sus posibilidades de convertirse en empresario (Gráfico 12).

Gráfico 12. Propensión empresarial de los potenciales sevillanos (\% sobre $n=182$ ).

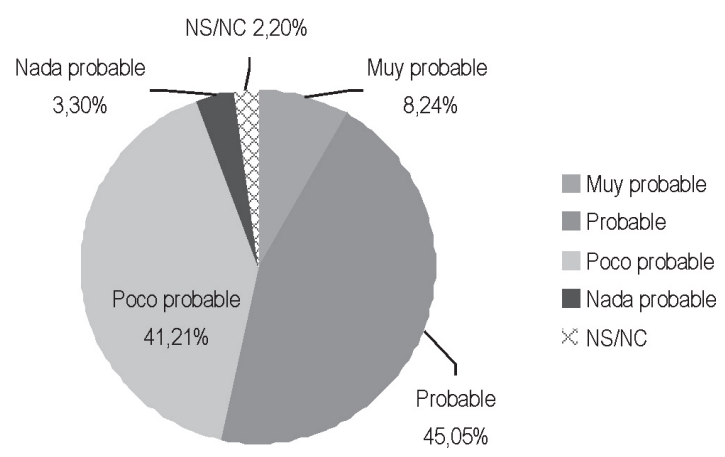

Fuente: Elaboración propia.

Por lo tanto, en referencia al conjunto de individuos de la muestra, únicamente el $34,89 \%$ presenta una orientación hacia el trabajo por cuenta propia y elevada propensión a la actividad empresarial; es decir, del total de la muestra sólo 98 
personas prefieren trabajar por cuenta propia y consideran probable o muy probable desempeñar con éxito en un futuro un comportamiento de emergencia empresarial. Estos resultados son algo inferiores a los obtenidos en el otro estudio sobre el potencial empresario sevillano al que anteriormente se ha hecho referencia, en el que la proporción de individuos que creen probable o muy probable llegar a ser empresarios se sitúa en el 37,6\% (Guzmán, 1995), lo que podría interpretarse argumentando que el potencial empresarial de la provincia está disminuyendo ligeramente $o$ en retroceso. Sin embargo, quizás sea un poco apresurado aventurar esta conclusión, especialmente si consideramos que los datos en los que nos hemos basado no son estadísticamente comparables (la metodología estadística y el universo poblacional empleado difieren en algunos elementos de los que se han utilizado en esta investigación) y sí insuficientes para considerar que existe una tendencia a la baja en cuanto al potencial empresarial sevillano. Lo que sí es posible concluir a la luz de los resultados obtenidos es que el potencial empresarial de la provincia de Sevilla es algo reducido, ya que menos del $35 \%$ de la población de esta provincia presenta una orientación hacia el trabajo por cuenta propia y una elevada propensión hacia la actividad empresarial.

Los resultados obtenidos hacen necesario un análisis más profundo del potencial empresarial sevillano para intentar descubrir cuáles son las causas que explican su reducido nivel. En este sentido, en el marco teórico descrito con anterioridad se consideró que la propensión de los individuos hacia la actividad empresarial dependía, en primer lugar, de sus preferencias por la actividad empresarial frente a otras actividades laborales, sean por cuenta propia o por cuenta ajena, y en segundo lugar, de sus percepciones acerca de la viabilidad de desempeñar esta actividad con éxito. Analizando las preferencias laborales de los individuos de la muestra, se obtienen unos resultados un tanto sorprendentes, ya que más del $68 \%$ de los individuos de la muestra, con orientación hacia el trabajo por cuenta propia prefieren ser empresarios frente a otras opciones de trabajo independiente, lo que, con relación al conjunto de la muestra, supone que casi el $45 \%$ de los sevillanos prefieren trabajar como empresarios antes que desempeñar cualquier otra actividad empresarial por cuenta ajena o propia.

En función de estos datos, parece lógico suponer que la reducida propensión hacia la actividad empresarial que se advierte que posee la población universitaria de Sevilla no se debe a que no desee emprender esta actividad, sino a su falta de 
confianza en la viabilidad de desempeñar esta actividad con éxito. En definitiva, la población universitaria de Sevilla posee un reducido nivel de potencial empresarial porque no percibe viable la posibilidad de llegar a emerger como empresario, lo cual podría deberse a la falta de confianza en sus propias capacidades para desempeñar tal comportamiento.

\subsection{Potencial empresarial femenino versus masculinos}

A continuación, la investigación se centrará en el estudio de las potenciales empresarias sevillanas, para intentar descubrir si en verdad su potencial empresarial es inferior al masculino y, en el caso de que así sea, a qué se debe. ¿a su escasa orientación hacia el trabajo por cuenta propia o a su reducida propensión hacia la actividad empresarial?

Analizando la orientación hacia el trabajo por cuenta propia en función del sexo se observa (Gráfico 13) que las mujeres poseen una menor orientación hacia la actividad empresarial que los hombres, pues tan sólo el 60,3\% de las 174 mujeres de la muestra señalaron preferir un trabajo por cuenta propia frente al $74 \%$ de los 104 hombres que también lo hicieron. En realidad, el porcentaje de mujeres que responden preferir un trabajo por cuenta propia no se distancia mucho de la media observada para el conjunto de la población $(65,47 \%)$, aunque sí es sorprendentemente reducido en comparación con el masculino, lo cual puede estar causado por la inferior propensión al riesgo que, según se ha descrito en diferentes estudios empíricos, parece caracterizar a las mujeres (Chaganti 1986, Kolvereid y Ljunggren1996). Un trabajo por cuenta propia permite disfrutar de una cierta independencia al no tener que estar sometido a una estructura jerárquica y a supervisión, pero por el contrario supone un mayor riesgo laboral, ya que entraña mayores problemas y responsabilidad para la persona que lo desempeña. Por otro lado, de la Gráfico 13 también se puede deducir que las mujeres sevillanas presentan un mayor grado de indecisión respecto a sus preferencias laborales, ya que una proporción importante de las mismas responde no sabe/no contesta cuando se les pregunta por su orientación hacia el trabajo por cuenta propia 0 ajena. 
Gráfico 13. Preferencias laborales de los potenciales empresarios sevillanos según su sexo.

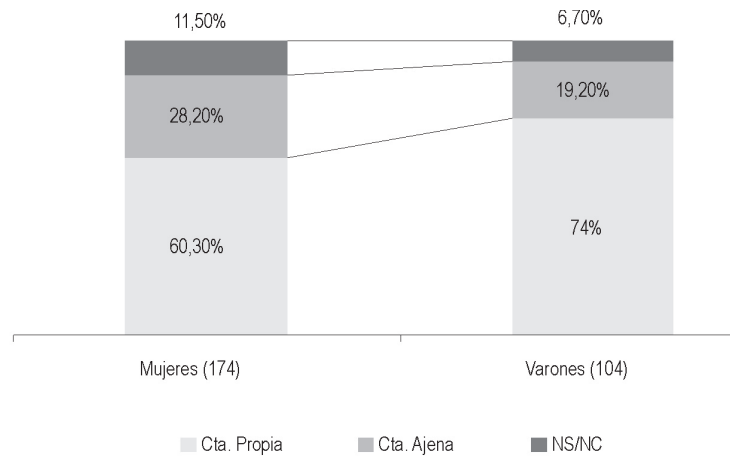

Fuente: Elaboración propia.

Comparando los resultados obtenidos con los extraídos del estudio del potencial empresarial de Sevilla realizado por Guzmán Cuevas en el año 1991 (Cuadro 20), se observa que hay una cierta coincidencia entre ambos, en el sentido de que en este trabajo también se advierte una menor orientación hacia el trabajo por cuenta propia entre las mujeres $(64,3 \%)$ que entre los potenciales empresarios masculinos (73,1\%) (Guzmán, 1995). No obstante, si la comparación la realizamos entre los grupos en función del sexo y el año de obtención de los resultados, se observa que existen algunas diferencias a resaltar: mientras que la orientación hacia el trabajo por cuenta propia ente los potenciales empresarios sevillanos de sexo masculino ha permanecido prácticamente estable en el tiempo, con un pequeñísimo aumento de apenas 0,9 puntos porcentuales, entre las potenciales empresarias ha disminuido sensiblemente (4 puntos porcentuales). En consecuencia, la distancia entre la orientación por cuenta ajena de ambos grupos de potenciales empresarios ha aumentado. En este sentido, podría deducirse que una de las posibles causas del retroceso del potencial empresarial sevillano vislumbrado en el epígrafe anterior se encontraría en el descenso de la orientación hacia el trabajo por cuenta propia entre las mujeres sevillanas en estos últimos nueve años: 
Cuadro 20. Preferencia por el trabajo por cuenta propia y ajena. (Porcentajes sobre total)

\begin{tabular}{|l|c|c|c|c|c|c|}
\hline & \multicolumn{3}{|c|}{ Año 2000 } & \multicolumn{3}{|c|}{ Año 1991 } \\
\hline & Cta. propia & Cta. Ajena & Total Muestra & Cta. Propia & Cta. ajena & Total Muestra \\
\hline Total & 65,47 & 24,82 & 278 & 69,0 & 31,0 & 1.238 \\
\hline Sexo & & & & & & \\
\hline Varones & 74,0 & 19,2 & 104 & 73,1 & 26,9 & 661 \\
\hline Mujeres & 60,3 & 28,2 & 174 & 64,3 & 35,7 & 577 \\
\hline
\end{tabular}

Fuente: Elaboración propia a partir de datos de Guzmán Cuevas, J. (1995) El empresariado en la provincia de Sevilla. Sevilla Siglo XXI. Diputación de Sevilla.

Por otro lado, la inferior orientación hacia el trabajo por cuenta propia que muestran las potenciales empresarias sevillanas respecto a sus congéneres del sexo masculino se ve reforzada por su menor propensión a la actividad empresarial (Gráfico 14), puesto que del total de mujeres encuestadas que respondieron preferir un trabajo por cuenta propia, únicamente el $45,7 \%$ considera probable o muy probable llegar a desempeñar una actividad empresarial en el futuro, porcentaje que en el caso de los hombres se eleva al $63,6 \%$. Se comprueba, además, que la inferior propensión hacia la actividad empresarial de las mujeres sevillanas respecto a los varones aumenta a medida que crece la probabilidad que el individuo cree que tiene de llegar a ser empresario. Así, el porcentaje de potenciales empresarios masculinos que considera muy probable llegar a ser empresarios es del $12,99 \%$ frente al $4,76 \%$ de las mujeres, es decir, por cada mujer claramente decidida a convertirse en empresaria, existen casi tres hombres en la misma situación. Esta diferencia apenas llega al 1,5 cuando se consideran únicamente los individuos de ambos sexos que sólo creen "probable" llegar en un futuro a ser titular de una empresa ( $50,65 \%$ en el caso de los hombres; $40,95 \%$ en el caso de las mujeres).

Por último, proporcionalmente son más numerosas las mujeres que, a pesar de preferir un trabajo por cuenta propia, no creen probable llegar a ser empresarias en un futuro, por lo que se podría deducir que las potenciales empresarias sevillanas perciben menos viable la posibilidad de emerger como empresarias que sus congéneres masculinos. 
Gráfico 14. Propensión empresarial de los potenciales sevillanos según su sexo (\% sobre $n=182)$.

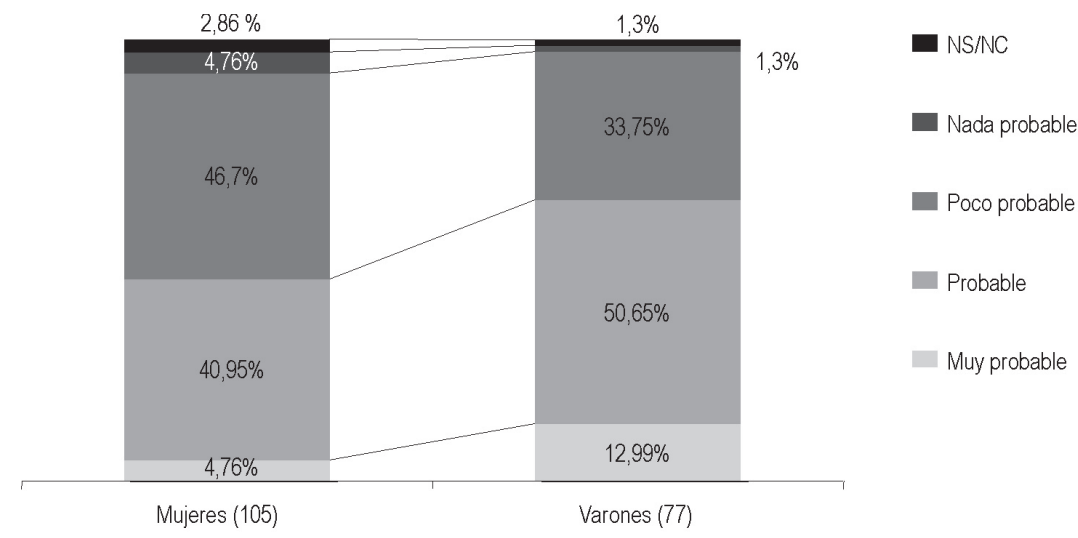

Fuente: Elaboración propia.

La inferior propensión hacia la actividad empresarial de las mujeres encuestadas hace necesario un análisis más profundo del potencial empresarial de los individuos encuestados para intentar descubrir si está causada por una reducida orientación hacia la actividad empresarial, o por una falta de confianza en la posibilidad de desarrollar una actividad empresarial con éxito. En la Cuadro 21. se expone la proporción de los individuos encuestados que presentan un elevado nivel de potencial empresarial, es decir, aquéllos que prefieren desarrollar una actividad empresarial antes que cualquier otra actividad laboral por cuenta propia o ajena y, además, creen probable o muy probable llegar a desempeñar dicha actividad con éxito en un futuro. En dicha tabla se puede observar que, a pesar de mantenerse la menor orientación hacia la actividad empresarial de las mujeres, la proporción de mujeres que desean ser empresarias sigue siendo elevada, ya que el $67,6 \%$ de las mujeres que desean un trabajo por cuenta propia prefieren trabajar como empresarias.

\section{Cuadro 21. Proporción de individuos con alto nivel de potencial empresarial según su sexo}

\begin{tabular}{|c|c|c|c|c|c|c|}
\hline & \multicolumn{4}{|c|}{ Orientación hacia la actividad empresarial } & \multirow{2}{*}{$\begin{array}{c}\text { Total Cta. } \\
\text { Propia }\end{array}$} & \multirow{2}{*}{$\begin{array}{c}\text { Total } \\
\text { muestra }\end{array}$} \\
\hline & Alta propensión & $\begin{array}{c}\text { Baja } \\
\text { propensión }\end{array}$ & NS/NC & Total & & \\
\hline $\begin{array}{l}\text { Mujeres } \\
\% \text { sobre total }\end{array}$ & $\begin{array}{c}35 \\
33,3 \%\end{array}$ & $\begin{array}{c}34 \\
32,38 \%\end{array}$ & $\begin{array}{c}2 \\
1,91 \%\end{array}$ & $\begin{array}{c}71 \\
67,6 \%\end{array}$ & $\begin{array}{c}105 \\
60,35 \%\end{array}$ & $\begin{array}{c}174 \\
100 \%\end{array}$ \\
\hline $\begin{array}{l}\text { Varones } \\
\% \text { sobre total }\end{array}$ & $\begin{array}{c}37 \\
48,05 \%\end{array}$ & $\begin{array}{c}17 \\
22,08 \%\end{array}$ & $\begin{array}{c}0 \\
0 \%\end{array}$ & $\begin{array}{c}54 \\
70,13 \%\end{array}$ & $\begin{array}{c}77 \\
74,03 \%\end{array}$ & $\begin{array}{c}104 \\
100 \%\end{array}$ \\
\hline Total & 72 & 51 & 2 & 125 & 182 & 278 \\
\hline
\end{tabular}

Fuente: Elaboración propia. 
No obstante, cuando estas mujeres evalúan cuáles son sus posibilidades reales de desarrollar tal actividad, su potencial se reduce casi hasta la mitad (sólo el $33,3 \%$ de las mujeres que desean ser empresarias considera probable o muy probable llegar a serlo, frente al $48,05 \%$ de los potenciales empresarios masculinos). Por lo tanto, la inferior propensión hacia la actividad empresarial de las potenciales empresarias sevillanas se debe más a una falta de confianza en sus propias capacidades y habilidades para desarrollar una actividad empresarial que a una falta de interés o deseo de desarrollar esta actividad. Esta falta de seguridad coincide con las observaciones realizadas en diversos trabajos de investigación acerca del menor grado de autoconfianza de las mujeres en general, y las potenciales empresarias en particular, las cuales dudan de su propia capacidad para adoptar y desempeñar un comportamiento empresarial con éxito. En este sentido, varios autores han relacionado la escasa confianza de las mujeres en sus propias capacidades empresariales con su menor nivel, frente a los varones, de preparación profesional específica para un adecuado comportamiento empresarial (Romero, 1990), y con su elevado grado de control interno, que les hace considerar que el éxito de este comportamiento depende más de ellas que de factores externos (Kolvereid y Ljunggren, 1996).

Comparando estos resultados con los obtenidos por el profesor Guzmán para el conjunto de la provincia de Sevilla en el año 1991 (Cuadro 22), se confirman las conclusiones anteriores referentes al menor potencial empresarial femenino al ser en ambos casos el porcentaje de mujeres con alta propensión hacia la actividad empresarial inferior al masculino, y viceversa, la proporción de mujeres con baja propensión empresarial es superior en ambos casos al masculino. Por otro lado, se observa que, tanto en el caso de las mujeres como de los varones, el numero de individuos con alta propensión hacia la actividad empresarial ha aumentado en términos relativos, de lo cual podría deducirse que la propensión empresarial de los potenciales empresarios sevillanos ha aumentado en el periodo de tiempo transcurrido entre ambos estudios. 
Cuadro 22. Propensión hacia la actividad empresarial. (Porcentajes sobre total población con orientación hacia el trabajo por cta. propia)

\begin{tabular}{|l|c|c|c|c|c|c|c|c|}
\hline & \multicolumn{4}{|c|}{ Año 2000 } & \multicolumn{3}{c|}{ Año 1991 } \\
\hline & $\begin{array}{c}\text { Alta } \\
\text { propensión }\end{array}$ & $\begin{array}{c}\text { Baja } \\
\text { Propensión }\end{array}$ & NS/NC & $\begin{array}{c}\text { Total } \\
\text { Muestra }\end{array}$ & $\begin{array}{c}\text { Alta } \\
\text { propensión }\end{array}$ & $\begin{array}{c}\text { Baja } \\
\text { propensión }\end{array}$ & NS/NC & $\begin{array}{c}\text { Total } \\
\text { Muestra }\end{array}$ \\
\hline Total & 53,3 & 44,5 & 2,20 & 182 & 37,6 & 53,4 & 8,9 & 854 \\
\hline Sexo & & & & & & & & \\
Varones & 63,6 & 35,1 & 1,3 & 77 & 46,1 & 46,5 & 7,4 & 483 \\
Mujeres & 45,7 & 51,5 & 2,86 & 105 & 27,9 & 61,6 & 10,6 & 371 \\
\hline
\end{tabular}

Fuente: Elaboración propia a partir de datos de Guzmán Cuevas, J. (1995) El empresariado en la provincia de Sevilla. Sevilla Siglo XXI. Diputación de Sevilla.

En definitiva, a la vista de los resultados obtenidos en este epígrafe se pueden extraer algunas conclusiones interesantes:

1. El nivel potencial empresarial de los universitarios de Sevilla no es muy elevado, ya que, extrapolando los datos de la muestra, únicamente el $34,89 \%$ de la población manifiesta una orientación hacia el trabajo por cuenta propia y una alta propensión hacia la actividad empresarial.

2. El reducido nivel de potencial empresarial que, según se advierte, posee la población universitaria sevillana no está causado por una escasa orientación hacia la actividad empresarial (que es bastante fuerte en los potenciales empresarios sevillanos), sino que se debe fundamentalmente a su falta de confianza en la viabilidad de adoptar un comportamiento empresarial con éxito, lo que afecta negativamente a su percepción de la posibilidad de llegar a emerger como empresario.

3. El potencial empresario universitario en Sevilla es preferentemente masculino, ya que las mujeres presentan un menor nivel de potencial empresarial que los hombres, tanto por su inferior orientación hacia la actividad empresarial como por su reducida propensión hacia la misma. Del total de varones de la muestra, más del $35 \%$ presenta un elevado nivel de potencial empresarial (manifiestan una preferencia por la actividad empresarial y consideran probable o muy probable llegar a ser empresarios), frente al $20,11 \%$ del total de mujeres encuestadas que se encuentran en esas circunstancias. 
4. Las potenciales empresarias universitarias de Sevilla presentan un menor deseo o necesidad de independencia en el trabajo, una menor confianza en sus propias capacidades para desarrollar actividades empresariales, una reducida propensión al riesgo, y un mayor grado de indecisión respecto a sus opciones laborales.

5. El potencial empresarial universitario de Sevilla podría haber aumentado en los últimos nueve años.

\subsection{Motivos que impulsan a los potenciales empresarios sevillanos hacia la actividad empresarial según su sexo}

Seguidamente se estudiarán cuáles son los motivos que impulsan a los potenciales empresarios universitarios sevillanos a iniciar una actividad empresarial estableciendo comparaciones entre géneros, para intentar descubrir las causas explicativas del menor potencial empresarial femenino.

Para analizar los motivos que impulsan a los potenciales empresarios sevillanos a iniciar una actividad empresarial, se preguntó a aquellos individuos de la muestra que habían respondido preferir dedicarse a la actividad empresarial antes que a cualquier otro trabajo por cuenta propia 0 ajena cuál era el principal motivo por el que esperaban dedicarse con mayor o menor probabilidad a esta actividad, observándose que, en general, existen una pluralidad de motivos por los que los potenciales empresarios sevillanos esperan dedicarse a la actividad empresarial, entre los que destacan los de carácter intrínsecos, seguidos a mucha distancia de los extrínsecos y, en un porcentaje casi insignificante, de los motivos trascendentales (Gráfico 15). Estos resultados se corresponden con la fuerte orientación hacia la actividad empresarial que presentan los potenciales empresarios sevillanos, ya que, como se ha mencionado anteriormente, los motivos de carácter intrínsecos están relacionados con la satisfacción que el individuo obtiene de forma directa al adoptar un determinado comportamiento. Por lo tanto, la preferencia o inclinación demostrada por los potenciales empresarios sevillanos respecto a la actividad empresarial se debe en parte a que les mueven motivos de carácter intrínseco, fundamentalmente la vocación empresarial ( $32 \%$ de los individuos de la muestra) y el deseo de realización $(24,8 \%)$. 
Gráfico 15. Motivos que impulsan a los potenciales empresarios sevillanos hacia la actividad empresarial. $(\%$ sobre $n=125)$.

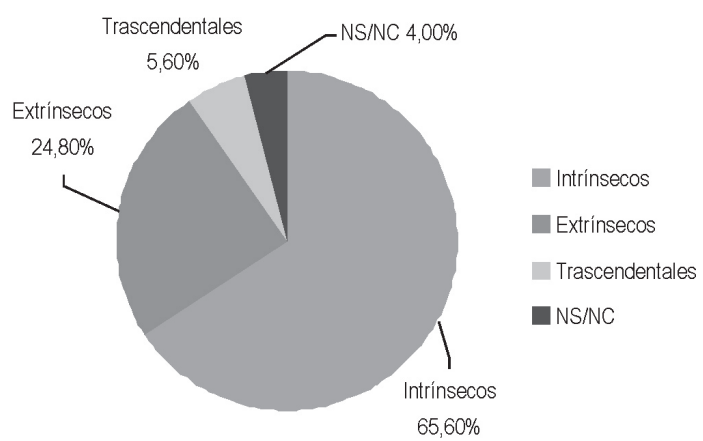

Fuente: Elaboración propia.

Centrándonos en las potenciales mujeres empresarias se observa que, en comparación con los potenciales empresarios de sexo masculino, no parece existir apenas diferencia en cuanto a la posición que ocupan en estos grupos los motivos de carácter intrínsecos, extrínsecos y trascendentales. No obstante, se aprecia que en el grupo de potenciales hombres empresarios el peso de las motivaciones de carácter intrínseco es, en conjunto, ligeramente inferior al peso que tienen este tipo de motivaciones entre sus semejantes de sexo femenino (Gráfico 15), diferencia que es a favor del sexo masculino en el caso de los motivos de carácter extrínseco y trascendental. 


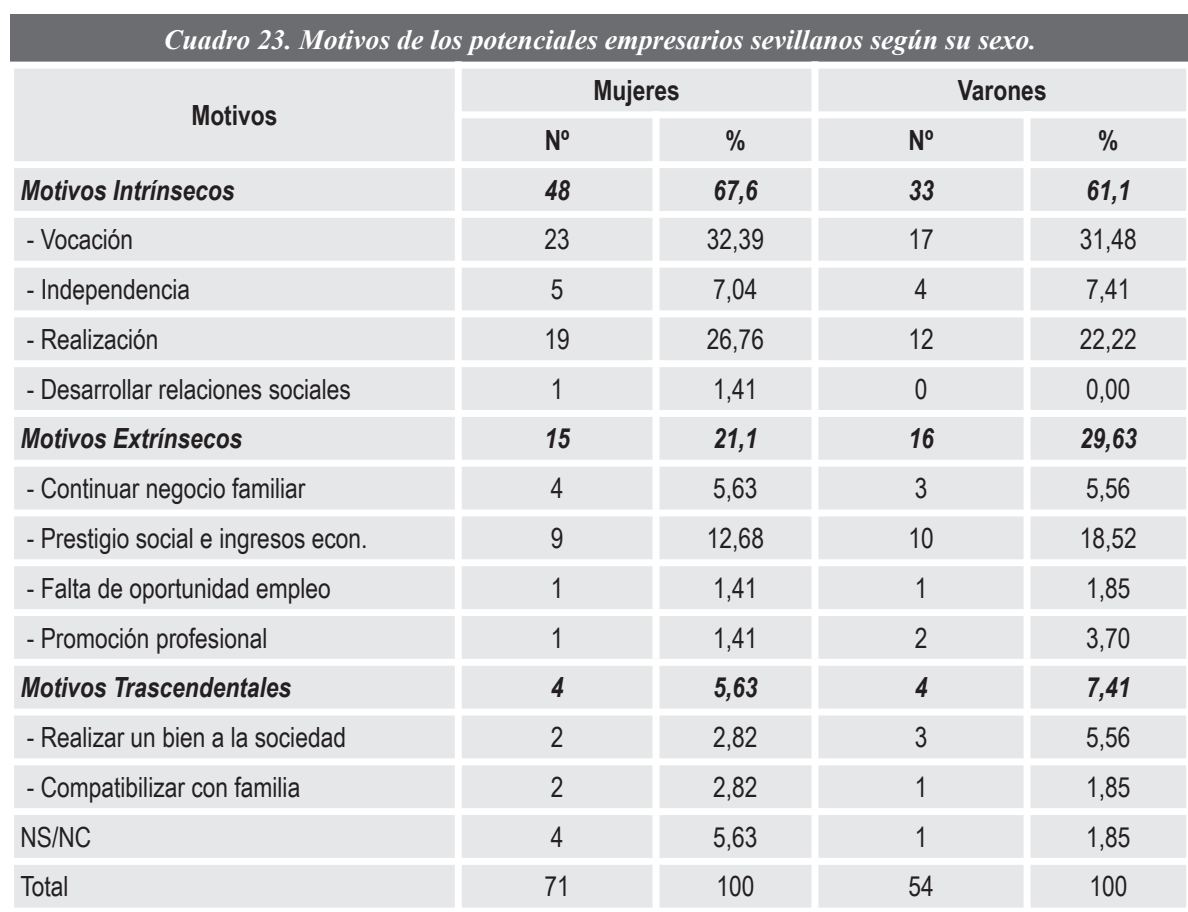

Fuente: Elaboración propia.

Así, las potenciales empresarias sevillanas presentan una vocación empresarial y deseo de realización superiores al de los varones y un mayor deseo de desarrollar las relaciones sociales, aunque la necesidad de independencia en el trabajo parece ser ligeramente más intensa en los varones de la muestra. Por el contrario, el grupo de potenciales empresarios masculinos se siente más preocupado por motivos extrínsecos tales como el prestigio social y la obtención de importantes ingresos económicos, y su interés por la actividad empresarial se debe en mayor medida a su superior deseo de independencia, a la dificultad de encontrar otro empleo y a la creencia de que mediante la actividad empresarial podrán promocionar más alto que trabajando por cuenta ajena. Finalmente, en cuanto a los motivos trascendentales, hay que señalar que mientras que un porcentaje mayor de mujeres que de hombres se inclinan a la actividad empresarial esperando tener más facilidades para compatibilizarla con su vida familiar, son proporcionalmente más numerosos los varones que lo hacen buscando realizar algo bueno para la sociedad. En este caso, y tal y como afirma Vinnicombe (1987), las estudiantes femeninas podrían estar considerando dedicarse a la actividad empresarial buscando encontrar una actividad 
laboral que les permita atender mejor las necesidades familiares y tareas domésticas, actividades en las que los varones participan cada vez más, pero que aún hoy, y más en la tradicional sociedad sevillana, siguen siendo principalmente responsabilidad de la mujer.

Estas diferencias van a influir en la forma e intensidad en que las características personales y factores del entorno personal y global de los potenciales empresarios les afectan dependiendo de su sexo. En este sentido, y tal como se mencionó previamente al establecer diferentes hipótesis sobre las potenciales empresarias, es de esperar que las mujeres, en comparación con sus semejantes varones, sean menos susceptibles a la influencia de aquellos factores vinculados directa o indirectamente a los resultados con los que el entorno responde a la acción de un individuo, que son los que se relacionan con las motivaciones de carácter extrínsecos, mientras que por el contrario van a ser más sensibles a aquellos elementos que están más relacionados con la satisfacción que el individuo obtiene por adoptar un determinado comportamiento con independencia de la respuesta que reciban del exterior, que son los que se vinculan con los motivos de carácter intrínsecos.

Por otro lado, estos resultados son algo diferentes a los obtenidos por Guzmán Cuevas en la investigación que realizó entre los potenciales empresarios sevillanos en el año 1991. En dicho estudio se observó, primero, que apenas existían diferencias entre los motivos que impulsaban a los potenciales empresarios de ambos sexos hacia la actividad empresarial, y, segundo, que, a pesar de ello, la vocación y el deseo de ganar dinero pesaban más en la inclinación de los hombres hacia la actividad empresarial que en las mujeres.

En conclusión, de los resultados obtenidos en el análisis de los motivos que empujan 0 atraen a los potenciales empresarios universitarios de Sevilla hacia la actividad empresarial se puede deducir que la fuerte inclinación que las mujeres sevillanas presentan hacia la actividad empresarial se corresponde con el hecho de que ellas consideren que son su vocación, y el deseo de desarrollarse profesionalmente las razones que les motivan a iniciar esta actividad. Por otro lado, el menor deseo de independencia que las mismas manifiestan respecto de los potenciales empresarios masculinos puede explicar por qué la orientación empresarial de las mujeres sevillanas es inferior a la de los hombres. 


\subsection{Percepción de las oportunidades y obstáculos existentes en el entorno para los potenciales empresarios sevillanos según su sexo}

Finalmente, se examinarán las impresiones que los potenciales empresarios universitarios de Sevilla tienen acerca de su entorno económico, para investigar si existen diferencias en función del sexo de los mismos en cuanto a su forma de percibir las oportunidades y obstáculos existentes al inicio de una actividad empresarial y cómo afectan estas percepciones a su potencial empresarial.

El nivel de oportunidades económicas existentes en el entorno para emprender una actividad empresarial, que influyen en la viabilidad con que el potencial empresario percibe que podrá desarrollar una actividad empresarial en el futuro al proporcionarle incentivos de mercado y facilitarle recursos que afectan al coste de iniciar una actividad empresarial, se hubiese podido valorar de una forma objetiva tomando como base datos extraídos de la realidad de la economía sevillana. Pero lo que realmente afecta al potencial empresario no es el nivel de oportunidades reales existentes en el entorno, que sí son determinantes para su emergencia empresarial, sino cómo percibe esas oportunidades el individuo, por lo que para analizar dicha percepción se pidió a los estudiantes de la muestra que hiciesen una valoración subjetiva de los principales obstáculos con los que creían que podrían encontrarse si quisieran crear su propia empresa.

Los resultados obtenidos indican que, en conjunto, los obstáculos que más peso tienen en los potenciales empresarios sevillanos se refieren fundamentalmente a aspectos que no dependen del propio individuo, sino de su entorno económico (importante presión fiscal, excesivos trámites burocráticos, dificultad de acceso a la financiación...), por lo que se puede alegar que los factores del entorno económico son percibidos de forma negativa por el potencial empresario sevillano, lo cual explica su reducida confianza en la viabilidad de emerger como empresario. En concreto, entre los obstáculos que son percibidos por los potenciales empresarios como más graves para crear una empresa o iniciar una actividad empresarial destacan, en primer lugar, la dificultad para acceder a la financiación (del total de individuos de la muestra, el $31,7 \%$ ha señalado este como el principal obstáculo), seguido de la alta competencia existente en el mercado (24,5\%), y en tercer lugar, a bastante distancia, la falta de formación empresarial $(10,8 \%)$. Estos resultados, de los que podría deducirse un cierto locus de control externo entre los potenciales empresarios universitarios, ya que 
creen que los resultados derivados de su comportamiento están más condicionados por factores externos que por factores internos controlados por ellos mismos, contrastan con el elevado porcentaje de potenciales empresarios que consideran que en el caso de crear una empresa o continuar un negocio familiar podrían contar con la ayuda de entidades financieras y/o de la administración pública (34,89\%).

Comparando los potenciales empresarios sevillanos de ambos sexos (Cuadro 24), se aprecia que, aunque un porcentaje elevado de individuos de ambos grupos coinciden en su valoración de los principales obstáculos al inicio de la actividad empresarial, en conjunto parece que los obstáculos de carácter personal tienen un mayor peso para las mujeres que para los hombres, lo cual podría deberse a una menor confianza de las estudiantes de la muestra en sus propias habilidades y capacidades para realizar determinadas actividades. Esta falta de confianza se ha asociado en diferentes estudios empíricos a que las mujeres poseen, y así lo perciben, una menor formación especifica en conocimientos directamente relacionados con el desarrollo de las funciones empresariales (Brush y Hisrich, 1983) y una reducida experiencia laboral en comparación con los varones (Carter, Eartner y Reynolds 1995). Esta circunstancia se ve acentuada por el hecho de que, debido a sus motivaciones, las potenciales empresarias son más sensibles a la influencia de los factores de su entorno personal, como es el nivel de formación y experiencia laboral, que a los factores del entorno global, como son los obstáculos de tipo económico. Estos resultados podrían explicar por qué las mujeres sevillanas tienen una menor propensión empresarial que los varones, pues, como afirma el "European Observatory for SME", las barreras a la emergencia empresarial afectan en mayor medida a las mujeres que a los hombres. 
Cuadro 24. Valoración de los principales obstáculos al inicio de la actividad empresarial por los potenciales empresarios sevillanos según su sexo

\begin{tabular}{|l|c|c|c|c|}
\hline \multicolumn{1}{|c|}{ Obstáculos } & \multicolumn{2}{|c|}{ Mujeres } & \multicolumn{3}{c|}{ Hombres } \\
\hline & No & $\%$ & $\mathbf{N}^{\circ}$ & $\%$ \\
\hline De carácter económico & 122 & 70,12 & 85 & 81,73 \\
\hline - Dificultad de acceso a la financiación & 55 & 31,6 & 33 & 31,7 \\
\hline - Alta competencia mercado & 42 & 24,1 & 26 & 25,0 \\
\hline - Excesivos trámites burocráticos & 13 & 7,5 & 12 & 11,5 \\
\hline - Excesiva presión fiscal & 10 & 5,7 & 8 & 7,7 \\
\hline - Falta de contacto con instit. Empresariales & 8 & 4,6 & 6 & 5,8 \\
\hline - Deficientes infraestructuras & 2 & 1,1 & 0 & 0 \\
\hline De carácter personal & 39 & 22,41 & 16 & 15,38 \\
\hline - Falta de formación empresarial & 20 & 11,5 & 10 & 9,6 \\
\hline - Falta vocación empresarial & 9 & 5,2 & 2 & 1,9 \\
\hline - Dificultad de compatibilizar con familia & 5 & 2,9 & 3 & 2,9 \\
\hline - Dificultad de actuar en un entorno masculino & 5 & 2,9 & 1 & 1,0 \\
\hline Otros & 4 & 2,3 & 1 & 1,0 \\
\hline NS/NC & 1 & 0,6 & 2 & 1,9 \\
\hline TOTAL & 174 & 100 & 104 & 100 \\
\hline
\end{tabular}

Fuente: Elaboración propia.

En este sentido, en páginas anteriores, se han relacionado las mayores dificultades existentes al inicio de la actividad empresarial para las mujeres con la actitud de la sociedad respecto al rol desempeñado por la mujer en el mercado laboral y en el hogar, considerándose que el potencial empresarial femenino se podrían ver afectado por esta cuestión. Para analizar este tema se preguntó a todos los estudiantes encuestados si creían que las mujeres tenían las mismas posibilidades de ser empresarias que los hombres y por qué consideraban que la participación de la mujer en la actividad empresarial era menor, observándose que más de la mitad de las estudiantes encuestadas $(55,75 \%)$ estimaban que las mujeres no tenían las mismas posibilidades de ser empresarias y estar en situación de igualdad como tales frente al hombre, opinión que no era compartida por los potenciales empresarios masculinos, quienes opinaban en un $65,4 \%$ que todos tienen las mismas posibilidades con independencia de su sexo. Estas diferencias se han relacionado con las mayores dificultades que, en general, las mujeres sevillanas encuentran para actuar en todas 
los ámbitos públicos, especialmente en el empresarial. Estas dificultades parecen estar fuertemente asentadas en la conciencia de la población encuestada, puesto que tanto los individuos de un sexo como los de otro consideraron que la participación de las mujeres en la actividad empresarial era menor porque las trabas del mundo empresarial eran mayores para las mujeres (el $40,2 \%$ de las mujeres y el $38,8 \%$ de los hombres). En función de estos datos, parece bastante lógico que las potenciales empresarias tengan una percepción más negativa de las condiciones del mercado para emprender una actividad empresarial, pues, aun cuando objetivamente el entorno económico fuese el mismo para ambos sexos, en la práctica ambos grupos, y más las mujeres, perciben que tendrán que enfrentar mayores obstáculos.

\section{CONCLUSIONES}

Los resultados obtenidos permiten concluir que el modelo que se presenta parece adecuado para aproximarse al estudio del potencial empresarial y a sus factores determinantes, ya que sobre la base del mismo se ha podido conocer algunas de las características de las potenciales empresarias universitarias que, además, confirman la veracidad de las hipótesis planteadas acerca del potencial empresarial femenino en comparación con el masculino.

En este sentido, se ha apreciado que las mujeres universitarias de Sevilla presentan un menor potencial empresarial que los varones debido a su inferior orientación hacia el trabajo por cuenta propia y propensión hacia la actividad empresarial. Estas características parecen estar relacionadas con las diferencias existente entre ambos sexos en cuanto a los motivos que les impulsan a emprender una actividad empresarial, con algunos de sus rasgos de personalidad y con la diferente percepción que los mismos tienen acerca de las oportunidades y barreras existentes en el entorno para emprender una actividad empresarial. Así, las potenciales empresarias universitarias presentan una menor orientación hacia la actividad empresarial que los potenciales hombres empresarios por tener un menor deseo de independencia en el trabajo, percibir que no tienen las mismas posibilidades de ser empresarias que los hombres debido a barreras socioculturales y considerar que las trabas a la emergencia empresarial son superiores para las mujeres que para los hombres. Del mismo modo, las potenciales empresarias sevillanas presentan una menor propensión hacia la actividad empresarial que los varones porque su confianza 
en la viabilidad de desempeñar un comportamiento emprendedor se ve menos reforzada por la experiencia laboral y formación especializada que la masculina, y tienen una visión más pesimista de las oportunidades y obstáculos existentes en el entorno para la creación de una nueva empresa o el inicio de una actividad empresarial.

\section{BIBLIOGRAFÍA}

Ajzen, I. (1991). "The theory of planned behavior". Organizational Behavior and Human Decission Process. Vol. 50(2). Pp. 1-63.

Alson, G.A. y Kolvereid, L. (1998). "The business gestación process differ by gender? A longitudinal study of nascent entrepreneurs". Frontiers of Entrepreneurs Research. Wellesley MA: Babson College.

Alsos, G.A. y Ljunggren, E. (1998). "Does the business Start-up process differ by gender? A Longitudinal Study of nascent entrepreneurs". Paper Presented to the Babson Frontiers of Entrepreneurs Research Conference. Wellesley MA: Babson College. http://www.babson.edu/entrep/fer/.

Allen, K.R. y Carter, N.M. (1997) . "Size determinants of women -owned business: choice or barriers to esources?". Entrepreneurship \& Regional Development, 9. Pp. 211-220.

Arora, R., Hartman, R. y Stoner, C. (1990) "Work-home Role Conflict in Female Owners of Small Businesses: An Exploratory Study". Journal of Small Business Management 28(1). Pp. 30-38.

Bateman, T. y Crant, M. (1993). "The proactive component of organizational behavior". Journal of Organizational Behavior 14 (2). Pp. 103-118.

Belcourt, M. (1987). "Sociological Correlate of Female entrepreneurship". Journal of Small Business and Entrepreneurship 4 (3).

Bellu, R.R. (1993) "Task role motivation and attributional style as predictors of entrepreneurial performance: Female Sample findings". Entrepreneurship and Regional Development, 5. Pp. 331-344. 
Benson, R. y Buttner, E.H. (1989). "Funding new business ventures: are decision makers biased against women entrepreneurs?". Journal of Business Venturing, 4. Pp. 249-261.

Birley, S. (1989)."Female Entrepreneurs: are they really any differents?". Journal of Small Business Management. 7(1). Pp. 7-31.

Birley, S., Moss, C y Saunders, P. (1987). "Do women entrepreneurs require different trainig?". American Journal of Small Business, 12 (1). Pp. 27-35.

Boden, R.J. y Nucci, A.R. (2000). "On the survival prospects of man's and women's new business ventures". Journal of business Venturing, 15 (4). Pp. 347-362.

Bowen, D. y Hisrich, R.D. (1986) "The females entrepreneurs: a career development perspective”. Journal of Management Review, 11(2). Pp. 393-407.

Boyd, N.G. y Vozikis, G.S. (1994). "The influence of self-efficacy on the development of Entrepreneurial intentions and actions". Entrepreneurship. Theory and Practice 18. Pp. 63-90.

Brazeal, D.V. y Krueger, N.F.Jr. (1994). "Entrepreneurial potential and potential entrepreneurs". Entrepreneurship Theory and Practice, Vol 18. (3). Pp. 91-105.

Brochklaus, R. y Horwitz, P. (1986). "The female entrepreneur. A career development perspective". Academy of Management Review 11, pp. 393-407.

Brodzinski, J.D., Scherer, R.F. y Wiebe, F.A. (1990). "Entrepreneurship Career Selection and Gender: A Socialization Approach". Journal of Small Business Management 28(2). Pp. 37-44.

Brush, C. (1992). "Research on Women Business Owners: Past Trends, a New Perspective and Future Directions". Entrepreneurship Theory and Practice 16(4). Pp. 5-30.

Brush, C. (1997). "Women-owned Businesses: Obstacles and Opportunities", Journal of Developmental Entrepreneurship 2(1). Pp. 1-25. 
Brush, C.G y Hisrich, R.D. y (1983). "The Woman Entrepreneur: Implications of Family, Educational, and Occupational Experience”, en Hornaday, J., Timmons, J. y Vesper, K. (eds.). Frontiers of Entrepreneurship Research. BabsonCollege, Wellesley, MA. Pp. 255-270.

Brush, C.G. y Hisrich, R.D. (1984). "The Women Entrepreneur: Management Skills and Business Problems". Journal of Small Business Management. 22(1). Pp. 30-37.

Brush, C.G. y Hisrich, R.D. (1991) "Antecedent influences on women -owned businesses". Journal of Managerial Psychology 6(2). Pp. 9-17.

Buttner, E. y Rosen, B. (1989), "Funding New Business Ventures: Are Decision Makers Biased against Women Entrepreneurs?". Journal of Business Venturing 4(4). Pp. 249261.

Cáceres Carrasco, F.R. (2001). Entorno socioeconómico y espiritu empresarial. Factores determinantes de la emergencia de empresarios en Andalucía Occidental. Servicio de publicaciones de la Universidad de Sevilla. En prensa.

Cáceres Carrasco, F.R. y Rodríguez Gutiérrez, M.J. (1998). Factores diferenciales en la emergencia empresarial según el sexo en Andalucía Occidental. XII Reunión Asepelt España. Córdoba.

Carland, J.W. y Carland, J.C. (1991). «An empirical investigation into the distinctions between male and female entrepreneurs and managers». International Small Business Journal, 9(3). Pp. 62-72.

Carland, J.W. y Carland, J.C. (1997). «A model of Potential Entrepreneurship: profiles and Educational Implications». Journal of Small Business Strategy, 8(11). Pp. 1-13.

Carsrud, A.L.; Krueger, N.F.Jr. y Reilly, M.D. (2000). "Competing models of entrepreneurial intentions". Journal of Business Venturing 15. Pp 411-432.

Carsrud, A.L.; Krueger, N.F.Jr. y Reilly, M.D. (2000). "Entrepreneurial intentions: applying the theory of planned behavior". Entrepreneurship and Regional Development. Vol. 5. Pp. 411-432.

Carter, N.M., Gartner, W.B. y Reynolds, P.D. (1996). "Exploring start-up event sequences". Journal of Business venturing, 11. Pp. 151-166. 
Cooper, A.; Srinivasan, R., y Woo, C. (1994). "Performance Determinants for Male and Female Entrepreneurs". Frontiers of Entrepreneurship Research Babson College, Wellesley, MA. Pp. 43-56.

Cromie, S. y Hayes, J. (1988). "Towards a typology of female entrepreneurs". The Sociological Review, 36(1). Pp. 87-113.

Chaganti, R. (1986) "Management in Women-Owned Enterprises". Journal of Small Business Management 24 (4), Pp.18-29.

Chaganti, R y Parasuraman, S. (1996). "A Study of the Impact of Gender on Business Performance and Management Patterns in Small Business". Entrepreneurship Theory and Practice 21(2). Pp. 73-76.

Currie, H.M. y Olson, S.F. (1992). "Female entrepreneurs: personal value systems and business strategies in a male-dominated industry". Journal of Small Business Management, 30(1). Pp. 49-57.

Doran, B.; Hsieh, S.; Rittenburg, T. y Van Auken, H. (1994). "An Empirical Analysis of Advertising by Women Entrepreneurs". Journal of Small Business Management 32(3). Pp. 10-28.

Doss, N., Mazzarol, T., Volery, T. y Thein, V. (1999). "Factors influencing small business start-ups. A comparison with previous research". International Journal of Entrepreneurial Behaviour \& Research 5(2). Vol. 5. № 2. Pp. 48-63.

European Network for SME Research (1997). Fifth annual report of the european observarory for SME. Comisión Europea.

European Network for SME Research (2000). Sixth annual report of the european observarory for SME. Comisión Europea.

Fagenson, E. y Marcus, E. (1991). «Perceptions of the Sex-role Stereotypic Characteristics of Entrepreneurs:Women's Evaluations». Entrepreneurship Theory and Practice 15(4). Pp. 33-47.

Fischer, E., Reuber, R. y Dyke, L. (1993). "A theoretical overview and extension of research on sex, gender and entrepreneurship". Journal of business Venturing 8(2).Pp. 151-168. 
Gartner, W.B. (1985). "A conceptual framework for describing the phenomenon of new venture creation”. Academy of Management Review, 10 (4). Pp. 696-706.

Gartner, W.B., Gatewood, E.J. y Shaver , K.G. (1995). "A longitudinal study of cognitive factors influencing start-up behaviors and success at venture creation". Journal of Business Venturing, 10 (5). Pp. 11-31.

Gibb Dyer, W.Jr. (1994). "Toward a theory of entrepreneurial careers". Entrepreneurship. Theory and Practice 19(2). Pp. 7-21.

Gibb, A.A. (1993). "The enterprise culture and education: undertanding enterprise education and its links with small business, entrepreneurship and wider educational goals". International Small Business Journal. Vol. 3, No 11. Pp. 11-34.

González Cruz, T. F. y Guillén, M. (1996). "Motivaciones para la creación de empresas", en Vélaz Rivas, J.I. Motivos y motivación en la empresa. Ed. Díaz de Santos: Madrid. Pp. 115-129.

Guzmán Cuevas, J.J. (1995). El empresario en la provincia de Sevilla. Diputación de Sevilla. Sociedad siglo XXI.

Guzmán Cuevas, J.; Cáceres Carrasco, F.R. y Rodríguez Gutiérrez, M.J. (1996). "Factores diferenciales en el potencial empresarial de la mujer en España". X Reunión Asepelt España. Albacete.

Hisrich, R. y O'Brien, M. (1981). "The Women Entrepreneur from a Business and Sociological Perspective". Frontiers of Entrepreneurship Research. Babson College, Wellesley, MA. Pp. 21-39.

Instituto de Estadísitica de Andalucía (2000). Anuario estadístico de Andalucía. Consejería de Economía y Hacienda. Junta de Andalucía. Sevilla.

INE (2000). Encuesta de Población Activa. Datos anuales y resultados detallados por trimestres.

Kent, C.A. y Sexton, D.L. (1981). "Female executives and entrepreneurs: a preliminary compararison". Frontiers of Entrepreneurship Research. Wellesley, Ma: Babson College. Pp. 40-46. 
Kolvereid, L. y Ljunggren, E. (1996). "New business formation: does gender make a difference?". Women in Management Review 11(4). Pp. 3-12.

Kolvereid, L.; Shane, S. y Westhead, P. (1993). "Is it equally difficult for female entrepreneurs to start businesses in all countries?". Journal of Small Business management 31(4). Pp. 43-51.

Krueger, N.F. (1993). "The impact of prior entrepreneurial exposure on perceptions of new venture feasibility and desirability". Entrepreneurship. Theory and Practice, 18(1). Pp. 5-21.

Lee, M y Rogoll, E. (1997) "Do women entrepreneurs require special training? An empirical comparison of men and women entrepreneurs in the United States". Journal of Small Business and Entrepreneurship, 14(1). Pp,4-27.

Marters, R. y Meier, R. (1988). "Sex difference and risk -taking propensity of entrepreneurs". Journal of Small Business Management. Vol. 26. Issue 1. Pp. 31-35.

Naciones Unidas (1986). Informe mundial sobre el papel de la mujer en el desarrollo. Departamento de Asuntos económicos y Sociales internacionales. Nueva York.

Naciones Unidas. (1995) Women in a changing global economy: World survey on the role of women in development. Nueva York.

OCDE (1997) "Conference on Women entrepreneurs in SMEs: a major force in innovatión and job creatión". Synthesis.

Pérez López, J.A. (1991) Teoría de la acción humana en las organizaciones: la acción personal. Rialp. Madrid.

Reynolds, P.D. (1992). "Sociology and entrepreneurship: concepts and contributions". Entrepreneurship. Theory and Practice, 16(2). Pp. 47-70.

Romero López, M. (1990). La actividad empresarial femenina en España. Instituto de la Mujer. Ministerio de Asuntos Sociales. Madrid.

Santos Cumplido, F.J. (2001). La calidad del empresario sevillano. Diputación de Sevilla. Sociedad Siglo XXI. 
Scott, C.E. (1986) "Why more women are becoming entrepreneurs?", Journal of Small Business Management, 24 (4). Pp. 37-44.

Shapero, A. (1981). "Self-renewing economies". Economic Development Commentary, 5. Pp. $19-22$.

Schwartz, E. (1976). "Entrepreneurship. A new female frontier". Journal of Contemporary Business, 53. Pp. 47-75.

Sexton, D.L. y Bowman-Upton, N.B. (1990). "Female and Male Entrepreneurs: Psychological Characteristics and Their Role in Gender-related Discrimination", Journal of Business Venturing 5, Pp. 29-36.

Stevenson, L.A. (1986) "Against all Odds: the entrepreneurship of women". Journal of Small Business Management, 24(4). Pp. 30-36.

Stevenson, L. (1990) "Some methological problems associated with researching women entrepreneurs" Journal of business ethics. № 9 Pp. 439-446.

Toribio Muñoz, R. (1998). El empresariado en la provincia de Cádiz. Diputación de Cádiz. Sevicios de Publicaciones. Cádiz.

Vázquez Barquero, A. (1999). "Desarrollo, Redes e Innovación". Lecciones sobre el Desarrollo Endógeno. Ed. Pirámide. Madrid.

Veciana Vergés, J.M. (1989). "Características del empresario en España". Papeles de Economía Española, n 39. Pp. 19-36.

Vélaz Rivas, J.I. (1996). Motivos y motivación en la empresa. Ed. Díaz de Santos: Madrid. Pp.257-278.

Vinnicombe, S. (1987). "Drawing out the differences between male and female working styles", Women in Management Review. Spring. 